\title{
Observations on the applicability of the Wartenberg pendulum test to healthy, elderly subjects
}

\author{
R A BROWN,* DOROTHY A LAWSON, G C LESLIE, N J PART \\ From the Department of Physiology and School of Mathematical Sciences, ${ }^{*}$ The University of Dundee, Dundee, \\ Scotland, UK
}

SUMMARY Wartenberg developed his pendulum test as a simple but precise test to assist examination of muscle tone in patients with Parkinson's disease. It has recently been reintroduced, and computerised, to evaluate spasticity in young hemiplegics. The results are reported on the highly successful application of this computerised test to large numbers of healthy, elderly subjects. The data have provided normal values for a number of measurements. Analysis of variance has shown that differences between individual subjects account for a major part of the total variabilities seen in all measurements taken. Factors such as position, leg and time trend contribute very little to total variation and, for practical purposes, can be ignored.

Spasticity, defined as "a condition resulting from hyperexcitability of the stretch reflex", ${ }^{1}$ is usually assessed in clinical practice by an investigator determining the resistance to passive manipulation of a limb. Whilst this method is simple to apply, the results are neither quantitative nor objective. This has led a number of investigators to assess spasticity by measuring the force developed by a limb as the result of a mechanically applied displacement at a controlled velocity. ${ }^{23}$ However, these techniques require specialised and often bulky equipment which make them unsuitable for use in the clinic. An alternative and more practical method is to generate movement by gravity, as Wartenberg ${ }^{4}$ did with his pendulum test for the assessment of Parkinsonian rigidity. In this test the patient is placed on a bench with the lower limb hanging freely from the knee. Following this, the examiner lifts the relaxed leg to the horizontal position and then releases it to swing freely under the action of gravity. As the lower leg swings down the quadriceps muscle is stretched, with any reflex contraction of that muscle modifying the swing pattern of the lower limb. This test has recently been reintroduced for the assessment of spasticity in young patients with spinal cord injury; ${ }^{5}$ the knee angle was measured with an electrogoniometer, allowing the subsequent analysis to be performed with the aid of a microcomputer. ${ }^{6}$

Address for reprint requests: Dr G C Leslie, Department of Physiology, The University of Dundee, Dundee, DDI 4HN, UK.

Received 27 November 1987 and in revised form 15 March 1988. Accepted 2 April 1988
The convenience of this computerised pendulum test suggested that it would be of practical use in the clinical investigation of muscle tone in large samples. It was first necessary however to apply the test to an elderly healthy population. This was important because the test is dependent upon the subject being quite relaxed and not in any way assisting or resisting the pendular movements. ${ }^{4}$ Whilst this is not a problem with paralysed patients ${ }^{5}$ it could be in elderly subjects. The results of this control study are reported here. Preliminary results have been presented to the Physiological Society. ${ }^{7}$ In the next paper ${ }^{8}$ we report results from elderly patients with stroke or Parkinsonism.

\section{Methods}

Two experiments, $A$ and B, were performed. In Experiment $A$ an elderly population was divided into three groups, each of which was tested in a different position. This was done because it was foreseen that it would not always be possible to place elderly patients in the full supine position as used by Bajd and Vodovnik. ${ }^{5}$ Experiment $B$ was made on a small group of young subjects, each being tested in all three positions.

\section{Experiment $A$}

One hundred volunteers, attending a SAGA Holiday's "Health Week", gave informed consent to take part in the study. Each individual was randomly assigned to one of three groups (S1, S2 and S3), (see table 1). Group S1 was investigated in the supine position, group $\mathrm{S} 2$ semi-supine with the back supported at an angle of $30^{\circ}$ to the horizontal on a wedge shaped pillow and group S3 sitting up. Goniometers (Penny and Giles Ltd, type 3410/3) were attached to 
Table 1 Randomised distribution of 100 subjects into experimental groups $S 1, S 2$ and $S 3$, together with each group's age statistics (mean, standard deviation $(\bar{X}, S D)$; numbers of subjects shown in parenthesis)

\begin{tabular}{llll}
\hline Group & & Female & Male \\
\hline S1 (34) & $\bar{X}$, SD & $67 \cdot 1,3 \cdot 9(27)$ & $68 \cdot 9,5 \cdot 8(7)$ \\
& range & $59-73$ & $58-76$ \\
S2 (30) & X, SD & $68 \cdot 1,6 \cdot 5(20)$ & $69 \cdot 5,4 \cdot 9(10)$ \\
& range & $58-86$ & $60-76$ \\
S3 (36) & $\bar{X}$, SD & $68 \cdot 3,4 \cdot 8(29)$ & $68 \cdot 7,4 \cdot 3(7)$ \\
& range & $60-78$ & $64-75$ \\
\hline
\end{tabular}

both legs for measurement of knee joint angles. Thereafter, the right leg was passively raised as near level with the examination couch as possible but without lifting the thigh off the couch. The investigator then encouraged the subject both to "relax" and to "let the limb be totally supported" (in the investigator's hand); experience as an investigator soon allowed one to determine when the subject's limb was relaxed and ready for release. On release the limb made a series of damped oscillations before coming to rest, with the knee joint angle at about $90^{\circ}$. This pattern only occurred provided the subject relaxed (see fig la) and did not assist or retard the movements (see fig 2a). After two trials, data were collected on a BBC microcomputer using its A/D converter and software produced by the Department of Bioengineering, University of Strathclyde. ${ }^{6}$ The investigator initiated the microcomputer to convert and store digitally the goniometer's output for 10 seconds, allowing about one second of recording "the start angle" before release. After each collection, the captured data were stored on disc. Six (occasionally seven) tests were made on both legs. Throughout the investigation we encouraged conversation, to relax and distract our subjects.
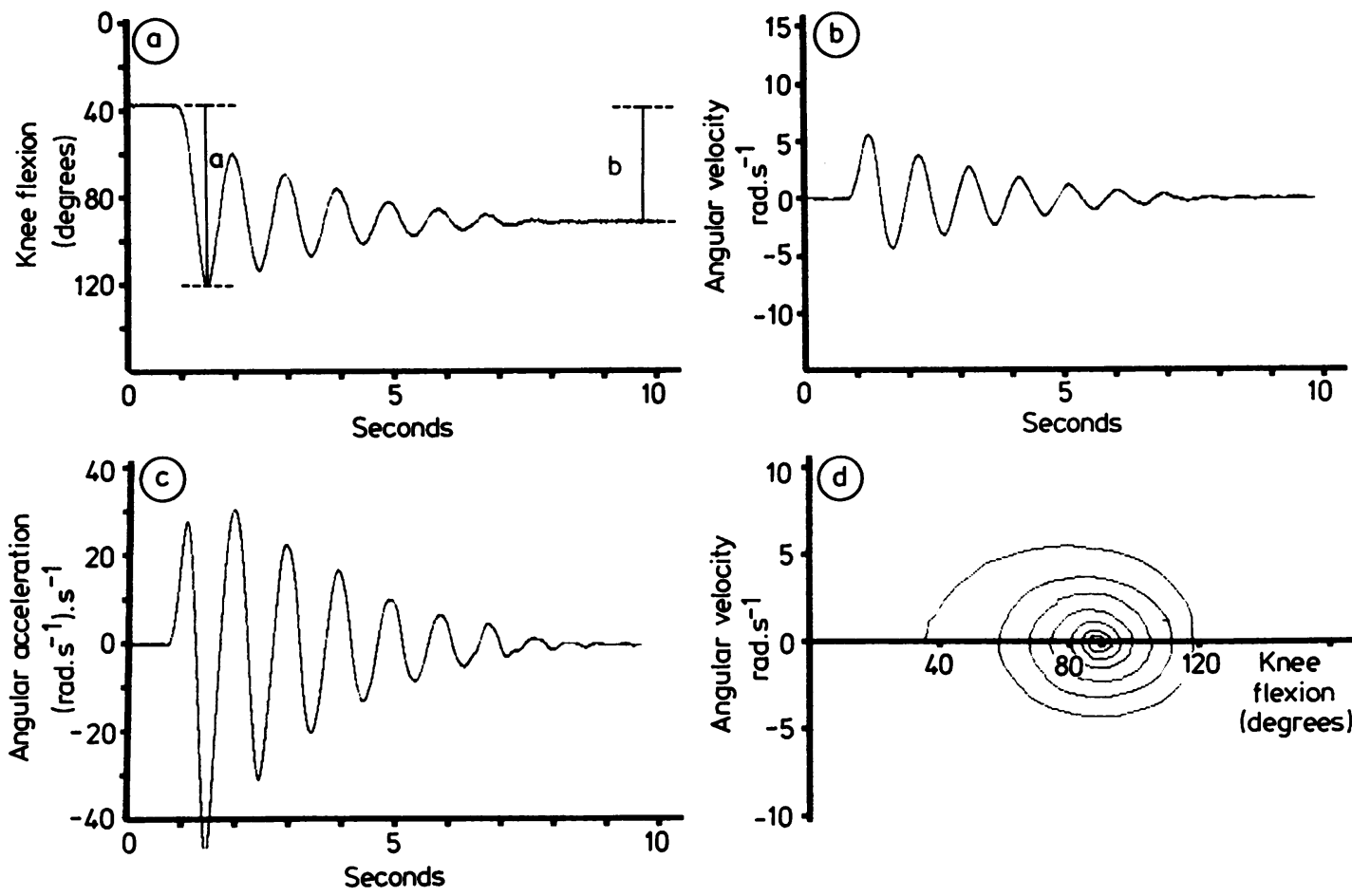

Fig 1 A typical set of four computer print-outs obtained from a single pendulum test on a totally relaxed and cooperative subject who was neither resisting or assisting the pendular movements. (1a) displays the angular changes occurring about the knee joint during seven damped oscillations following release of the subject's leg. The bar marked " $a$ " indicates the amplitude of the first swing, the bar marked " $b$ " the difference in angle between the start and end positions of the limb. The relaxation index (ratio, $R 2$ ), defined by Bowman and Bajd, ${ }^{10}$ is $a / b$, and in this case is 1.532 . (Ib) displays the first derivative of the trace shown in $(a)$. The maximum velocity occurring during the first swing is clearly seen and has a value of $5.55 \mathrm{rad}_{\mathrm{sec}}{ }^{-1}$. (1c) displays the second derivative of the original data, hence it illustrates the accelerations occurring during the swing and rebound phases of the pendular movements. The acceleration on the first swing peaks at 27.7 (rad.sec $\left.{ }^{-1}\right) . \mathrm{sec}^{-1}$. The maximum acceleration on the rebound from the first swing is in this illustration truncated but from analysis of the stored data is $-47 \cdot 7\left(\mathrm{rad}_{\mathrm{sec}} \mathrm{s}^{-1}\right) \mathrm{sec}^{-1} .(\mathrm{ld})$ is a display referred to as a "phase (plane) plot" and produced by plotting the velocity data (of b) against the angle data (of a). This form of "whirlpool" display show's up with remarkable ease any voluntary input by the subject (see fig $2 b$ ) or aberration of response, as from the affected limb of stroke patients (see reference (8), fig 1). 

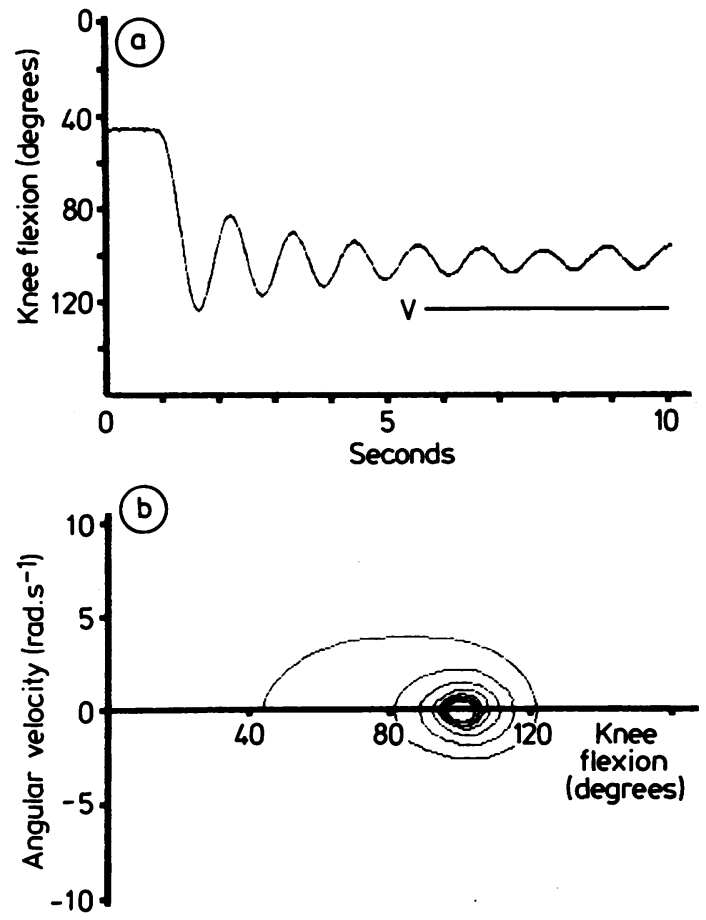

Fig 2 Two computer print-outs from the same pendulum test on a subject who, in the latter part of the recording, actively assisted the movements. (2a) displays the angular changes occurring about the knee joint following release of the subject's leg. After 4 damped oscillations, there is at point " $v$ " on the record a clear change to increased amplitudes of swing, caused by voluntary assistance from this "cooperative" subject. (2b) is the phase plot relating to the same test as the angle data shown in (2a). The additional "whirls" toward the centre of the plot mark clearly the subject's voluntary input over and above the expected natural and damped oscillations.

\section{Experiment $B$}

The subjects who took part in this supplementary experiment were five females and four males, aged between 19 and 24 years. The experimental protocol was the same as above, except that each individual was tested in all three positions.

\section{Data handling}

The test data were recalled from disc storage for further analyses and displays, using a modified and extended version of the software package donated by the Bioengineering Department of Strathclyde University. Measurements obtained from each pendulum test were: (1), relaxation index (R2), a ratio relating to angle; (2), the first maximum velocity; (3), the first maximum acceleration; and (4), the maximum acceleration on the first rebound swing; these measurements can be identified from inspection of fig $1 \mathrm{a}, \mathrm{lb}$ and lc. Test data from four subjects were excluded from final statistics because of their volunteering information about having attended a neurological clinic.
All acceptable data were entered into the University's mainframe computer (DEC 10), for statistical analysis using Version $\mathrm{H}$ release 9 of the Statistical Package for Social Sciences. ${ }^{9}$ Each set of measurements was subjected to multifactor analyses of variance for repeated measures data, in order to assess the factorial effects of subject, position, leg and time sequence.

In addition to conventional presentation of statistics (mean, standard deviation (SD) or mean, standard error of the mean (SEM)) we have also used the graphic method of "Box and Whisker" plots (see fig 3). Such presentations, by their markers, provide five items of data. The box indicates the middle $50 \%$ of the data values between the upper and lower quartiles, the line within the box is the median value, and the "whiskers" extend to the extremes of the range. Thus one may visualise the overall range, the nature of the distribution, with a measure of its variability and any tendency to skewness.

\section{Results}

Figure 1 gives an example of the records obtained, namely the angle data, the first differential of the angle and the second derivative of the original data. These records were analysed by the microcomputer to measure relaxation index, maximum velocity (on first swing) and maximum accelerations on first swing and its rebound (see below). Figure $1 d$ shows an $x-y$ plot of the angular data of fig la against the velocity data of fig $1 \mathrm{~b}$. This type of display shows up very sensitively any deviations from simple damped oscillations (see fig $2 b$, also fig 1 in reference 8 ).

\section{Relaxation index}

The typical record of knee joint angle (fig la) is very similar to that published for a normal subject by Bajd and Vodovnik. ${ }^{5}$ The relaxation index (R2) was measured from such records. Bowman and Bajd ${ }^{10}$ defined $\mathrm{R} 2$ as the ratio between the magnitude of the first drop (labelled $a$ in fig la) and the magnitude of the difference between initial and final angles (b in fig la). Thus in fig la, the magnitude of the first swing was $84^{\circ}$, the magnitude of the difference was $(92-37)^{\circ}$ and the relaxation index was 1.536 . Mean values for the data from the six tests on each individual leg were gathered together into group means and standard deviations (see table 2).

Analysis of variance was performed to determine the effects of (1) subject effect, (2) position effect, (3) leg effect, (4) time (trend) effect and (5) unaccounted for factors. Table 3 gives the percentage contribution to total variability in the data attributable to differences between individuals, that is subject effect. Intersubject variability represented more than half of the explainable variation in our relaxation index data. For comparison with this major ( $>50 \%$ ) component of variability, the percentage contributions by the other known factors is shown in table 4. In all cases 

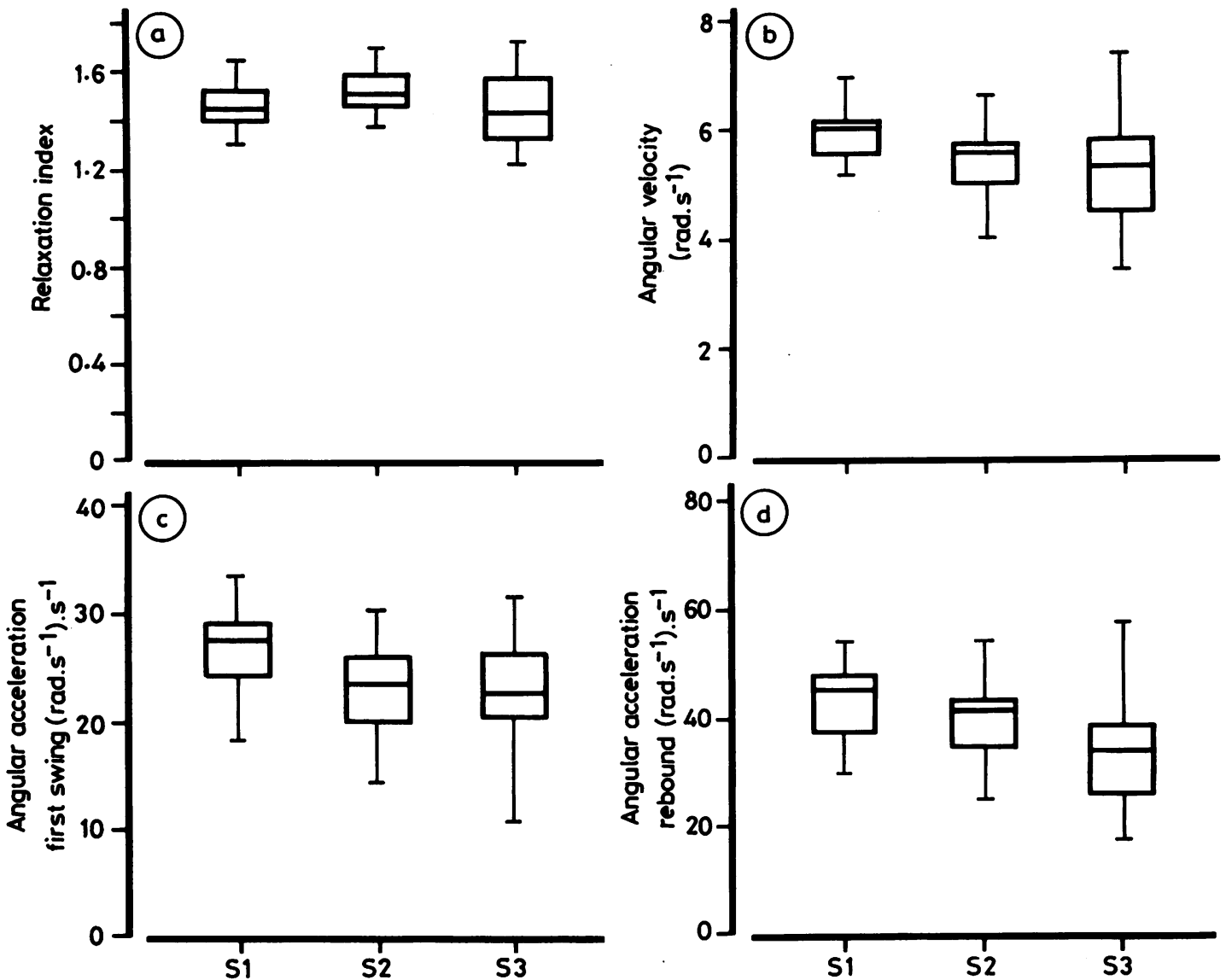

Fig 3 A composite series of "Box and Whisker" plots summarising statistical data from the three groups. (S1, S2 and S3). The four quadrants are of identical form: each box incorporates the central $50 \%$ of the values, the bar within the box indicates the median value, and the outer bars mark the extremes of the distributions. The data in the quadrants refer to (a) relaxation index, (b) maximum velocity on the first swing, (c) maximum acceleration on the first swing and (d) maximum acceleration on the first rebound. Note change in scale between $(c)$ and $(d)$.

Table 2 The data (mean, SD) for the four measurements ( $R 2$, velocity, acceleration and rebound acceleration), in each of the experimental positions for both legs in the elderly (SAGA) and young adult sample populations

\begin{tabular}{|c|c|c|c|c|c|}
\hline & & $R 2$ & Velocity & Acceleration & $\begin{array}{l}\text { Rebound } \\
\text { acceleration }\end{array}$ \\
\hline \multicolumn{6}{|c|}{ Expt. $A(S A G A)$} \\
\hline supine & $\begin{array}{l}\text { Left } \\
\text { Right }\end{array}$ & $\begin{array}{l}1 \cdot 50,0.09 \\
1 \cdot 50,0.09\end{array}$ & $\begin{array}{l}6 \cdot 16,0.53 \\
6 \cdot 44,0.56\end{array}$ & $\begin{array}{l}27 \cdot 5,3 \cdot 2 \\
31 \cdot 3,5 \cdot 1\end{array}$ & $\begin{array}{l}-47 \cdot 0,6 \cdot 2 \\
-50 \cdot 0,7 \cdot 4\end{array}$ \\
\hline semi-supine & $\begin{array}{l}\text { Left } \\
\text { Right }\end{array}$ & $\begin{array}{l}1 \cdot 55,0.09 \\
1.52,0.09\end{array}$ & $\begin{array}{l}5 \cdot 62,0 \cdot 72 \\
5 \cdot 88,0 \cdot 65\end{array}$ & $\begin{array}{l}24 \cdot 5,4 \cdot 1 \\
27 \cdot 7,4 \cdot 9\end{array}$ & $\begin{array}{l}-41 \cdot 8,7 \cdot 9 \\
-43 \cdot 3,8 \cdot 0\end{array}$ \\
\hline sitting up & $\begin{array}{l}\text { Left } \\
\text { Right }\end{array}$ & $\begin{array}{l}1.47,0.15 \\
1.48,0.15\end{array}$ & $\begin{array}{l}5 \cdot 34,0.86 \\
5 \cdot 75,0.96\end{array}$ & $\begin{array}{l}23 \cdot 9,4 \cdot 6 \\
25 \cdot 7,5 \cdot 4\end{array}$ & $\begin{array}{l}-36 \cdot 1,8 \cdot 8 \\
-40 \cdot 2,11 \cdot 5\end{array}$ \\
\hline \multicolumn{6}{|c|}{ Expt. B (young adults) } \\
\hline supine & $\begin{array}{l}\text { Left } \\
\text { Right }\end{array}$ & $\begin{array}{l}1.63,0.11 \\
1.56,0.10\end{array}$ & $\begin{array}{l}4 \cdot 91,0 \cdot 31 \\
4 \cdot 92.0 \cdot 66\end{array}$ & $\begin{array}{l}22 \cdot 3,2 \cdot 0 \\
24 \cdot 9,4 \cdot 0\end{array}$ & $\begin{array}{l}-34.9,3.4 \\
-35 \cdot 9,6 \cdot 1\end{array}$ \\
\hline semi-supine & $\begin{array}{l}\text { Left } \\
\text { Right }\end{array}$ & $\begin{array}{l}1.69,0.09 \\
1.64,0.10\end{array}$ & $\begin{array}{l}5 \cdot 09,0.41 \\
5 \cdot 11,0.53\end{array}$ & $\begin{array}{l}23 \cdot 6,2 \cdot 2 \\
25 \cdot 7,3 \cdot 9\end{array}$ & $\begin{array}{l}-35 \cdot 9,4 \cdot 4 \\
-34 \cdot 9,6 \cdot 4\end{array}$ \\
\hline sitting up & $\begin{array}{l}\text { Left } \\
\text { Right }\end{array}$ & $\begin{array}{l}1 \cdot 62,0.16 \\
1.57,0.15\end{array}$ & $\begin{array}{l}5.09,0.55 \\
5 \cdot 22,0.65\end{array}$ & $\begin{array}{l}24 \cdot 4,2 \cdot 4 \\
26 \cdot 1,4 \cdot 9\end{array}$ & $\begin{array}{l}-36 \cdot 3,6 \cdot 2 \\
-37 \cdot 7,7 \cdot 1\end{array}$ \\
\hline
\end{tabular}

these factors contribute little, the greatest for $\mathbf{R} 2$ being $4 \cdot 2 \%$. Figure 3a shows "Box and Whisker" plots of the data from the subjects in the three positions taking into account the variabilities from the minor factors. Variation in the relaxation index is greatest for group S3, bearing out our subjective impression that the test

Table 3 The percentage of total variability attributable to differences between subjects is shown when the total variability in the data associated with any one measurement (e.g. Relaxation index, R2) is set to $100 \%$

Rebound R2 Velocity Acceleration acceleration

Expt. A (SAGA)

(group S1)

(group S2)

(group S3)

Expt. B (young adults)
$38 \% 38 \%-35 \%$

$57 \% \quad 62 \% \quad 50 \%$

$70 \% 66 \% \quad 51 \%$

$53 \% \quad 47 \% \quad 39 \%$
$44 \%$

$69 \%$

$68 \%$ 
Table 4 The percentage of the total variability that can be explained in terms of experimental factors other than that between subjects (for comparison with table 3)

\begin{tabular}{|c|c|c|c|}
\hline & $\boldsymbol{R 2}$ & Velocity Acceleration & $\begin{array}{l}\text { Rebound } \\
\text { acceleration }\end{array}$ \\
\hline \multicolumn{4}{|c|}{ Expt. $A(S A G A)$} \\
\hline $\begin{array}{l}\text { leg } \\
\text { time } \\
\text { position }\end{array}$ & $\begin{array}{r}<0.1 \% \\
1.7 \% \\
4.2 \%\end{array}$ & $\begin{array}{rr}0.9 \% & 1.7 \% \\
3.0 \% & 5.0 \% \\
11.4 \% & 9.7 \%\end{array}$ & $\begin{array}{r}0.3 \% \\
2.0 \% \\
16.0 \%\end{array}$ \\
\hline \multicolumn{4}{|c|}{ Expt. B (young adults) } \\
\hline $\begin{array}{l}\text { leg } \\
\text { time } \\
\text { position }\end{array}$ & $\begin{array}{r}<0.1 \% \\
<0.1 \% \\
0.1 \%\end{array}$ & $\begin{array}{rr}<0.1 \% & 0.1 \% \\
<0.1 \% & <0.1 \% \\
0.1 \% & 0.1 \%\end{array}$ & $\begin{array}{l}<0.1 \% \\
<0.1 \% \\
<0.1 \%\end{array}$ \\
\hline
\end{tabular}

was most difficult to regulate when the subject was in the sitting position.

\section{Maximum velocity (first swing)}

Differentiation of the angle data (fig 1a) gave data on velocities (fig lb). Data relating to peak velocity on first swing were treated in the same manner as the relaxation index data (table 2). Table 3 shows that intersubject effect was again the major contributing factor to the total variability in the velocity data. The other known factors (table 4) made only a minor contribution, save for the $11.4 \%$ contribution applicable to the position effect in Experiment A. After adjustment for the relatively minor influences of position, leg and time trend, the distribution of the estimated subject effects for maximum velocity is as shown in fig 3b. Again the largest range of data was found in group S3.

\section{Accelerations (first swings)}

The second derivative of the angle data (fig la) yielded acceleration with its maxima for the first (downward) and rebound (forward) swing, calculated as positive and negative values respectively (fig $1 \mathrm{c}$, table 2 ). In all individual cases the maximum acceleration on the first rebound swing was greater than that on the initial swing; this might well be a reflection of the thixotropic property of muscle. ${ }^{11}$ Tables 3 and 4 and figs $3 c$ and 3d show that: (1) intersubject effect is the greatest contributor to the variations in the data for acceleration and rebound acceleration; (2) of the other influential effects, their percentage contributions to variation are small, except for position in Experiment $A ;(3)$ the largest ranges in the adjusted distributions are in group $\mathbf{S 3}$.

The major conclusion from the statistics is that, in both experiments $A$ and $B$, the intersubject variability on all four measurements (R2, maximum velocity, acceleration and rebound acceleration) is much greater than any effects attributable to differences between position, legs or time sequence. A number of
Table 5 The collected statistics of the estimates of the effects (mean, SEM) which were judged to be significant at the $1 \%$ level or better for the four measurements (R2, velocity, acceleration and rebound acceleration). Pos $1=$ supine: pos 2 = semi-supine: pos 3 = sitting up

\begin{tabular}{|c|c|c|c|c|}
\hline & $R 2$ & Velocity & Acceleration & $\begin{array}{l}\text { Rebound } \\
\text { acceleration }\end{array}$ \\
\hline \multicolumn{5}{|c|}{ Expt. A (SAGA) } \\
\hline $\begin{array}{l}\text { legs } \\
\text { time } \\
\text { pos } 1 \text { v } 2 \\
\text { pos } 1 \text { v } 3\end{array}$ & $\begin{array}{l}\text { NS } \\
0.08,0.03 \\
\theta 04, \theta-04 \\
0.03,0.01\end{array}$ & $\begin{array}{l}0.27,0.08 \\
0.06,0.02 \\
0.51,0.07 \\
0.76,0.06\end{array}$ & $\begin{array}{l}3 \cdot 2,0.6 \\
0 \cdot 4,0 \cdot 2 \\
3 \cdot 1,0 \cdot 5 \\
4 \cdot 7,0.4\end{array}$ & $\begin{array}{r}2.6,0.9 \\
1.0,0.3 \\
5.6,0.8 \\
10.4,0.7\end{array}$ \\
\hline $\begin{array}{l}\text { Expt. } B(3) \\
\text { legs } \\
\text { time } \\
\text { pos } 1 \text { v } 2 \\
\text { pos } 1 \text { v } 3\end{array}$ & $\begin{array}{l}\text { ults) } \\
0.06,0.01 \\
\text { NS } \\
0.07,0.01 \\
\text { NS }\end{array}$ & $\begin{array}{l}\text { NS } \\
\text { NS } \\
0.19,0.06 \\
0.23,0.06\end{array}$ & $\begin{array}{l}2 \cdot 2,0.3 \\
\text { NS } \\
1 \cdot 0,0.4 \\
1 \cdot 7,0.4\end{array}$ & $\begin{array}{l}\text { NS } \\
\text { NS } \\
\text { NS } \\
\text { NS }\end{array}$ \\
\hline
\end{tabular}

effects attributable to positions, legs and time were found to be statistically significant (table 5), chiefly because of the large sample size. In practice these differences are insignificant when investigating individual subjects (see Discussion).

\section{Maximum velocity against relaxation index}

Figure 4 shows plots of maximum velocity (on first swing) against relaxation index for the three groups of elderly subjects. If a perimeter is drawn round the extremes of the points in the distribution then there is produced the convex hull for that data. This has been done for the distributions in each of figs $4 a, 4 b$ and $4 c$, and the three hulls superimposed on one another in fig 4d. Figure 4d, with its presentation of convex hulls not only reinforces the relatively minor contribution of subject position to overall variability in data between control groups but provides also a means of illustrating the "area of normality" against which can be compared data from neurological patients. ${ }^{8}$

\section{Discussion}

We felt it important to collect the control data from elderly subjects prior to obtaining data from elderly neurological patients. The pendulum test was satisfactorily applied to 100 subjects aged from 58 to 86 years. The vast majority of subjects could both properly relax and avoid either assisting or resisting the pendular movements of the leg, a prerequisite for successful measurements. The minority (some five subjects) tended to assist rather than resist the pendular movements, but only did so after two or three unassisted swings. Such "co-operation" was easily recognisable on the records (see fig 2) but, since all our measurements were associated with the first swing and its immediate rebound (see figs 1a, 1 b and 1c), their 


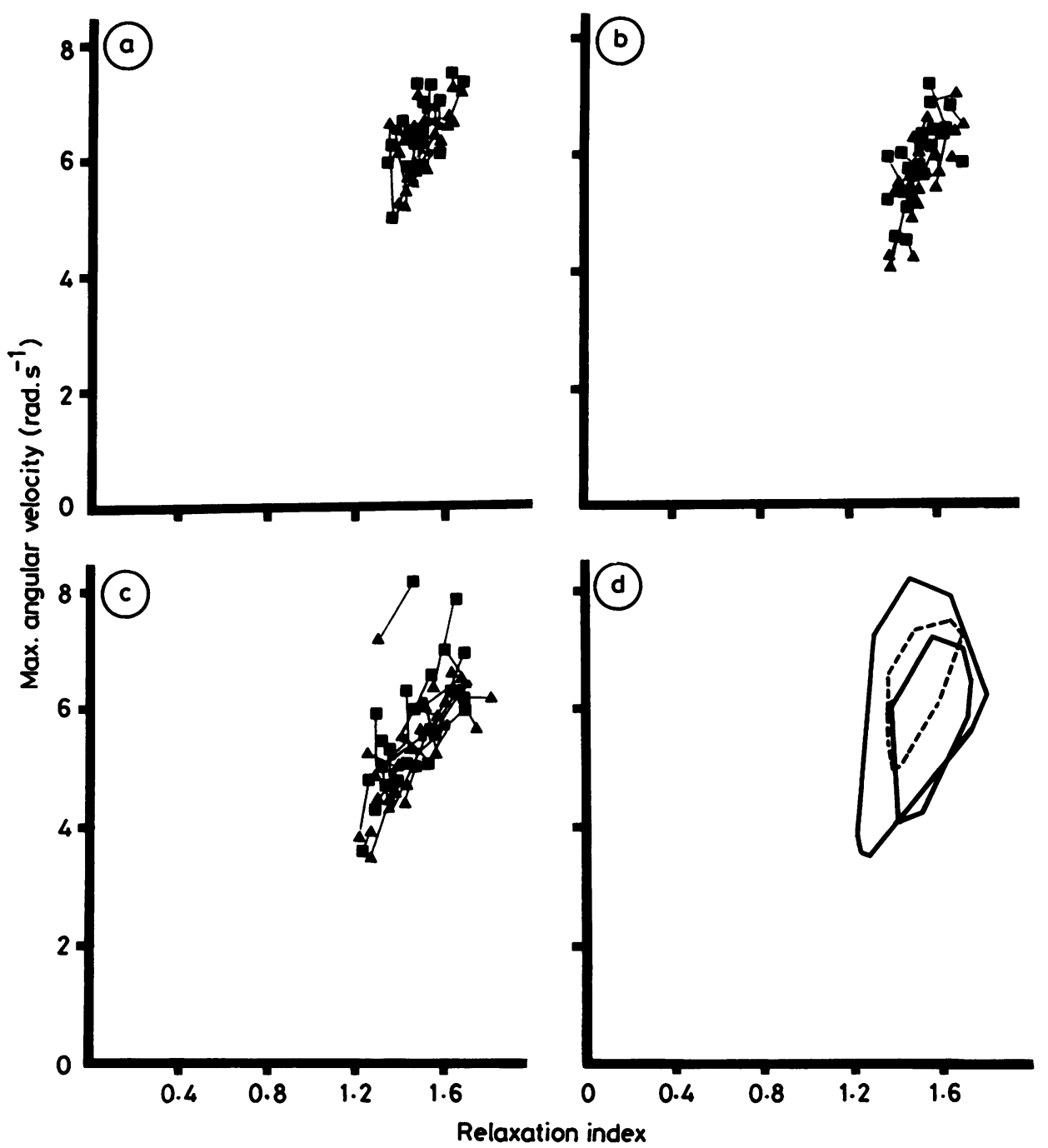

Fig 4 The relationship between relaxation index and maximum velocity on first swing for individuals, for groups, with summary. (4a) displays the data from the 34 subjects in group S1, assigned to take the test in the fully supine position. The filled triangles and squares represent the data from the right and left legs respectively: individual's data are joined by line. Both the small variability in individual's data and the larger scatter between subjects can be appreciated. (4b) displays the data from group $S 2$, tested in the semi-supine position. (4c) displays data from $S 3$, the group tested in the sitting up position. (4d) is a summary display of all the data shown in the other three panels. It consists of superimposed convex hulls. Each convex hull was formed from a perimeter line drawn round the extremities of the distributed relationship of the group. The innermost hull (---) is from group $S 1$, that from group $S 2$ (-) overlaps, and the largest, overlaying both, is that of S3. This compact form of summary illustrates the small but increasing variability that occurs in these data as a result of positional changes from lying, through semi-supine to sitting. Each hull also determines the area of normality for this relationship in each of the test positions.

later voluntary assistance did not invalidate the measurements made. Thus overall, we are confident that the pendulum test can be used on elderly subjects.

Statistical analysis has shown that, in a sample pop- ulation, intersubject variability is the major contributor to overall variation, in all measurements taken. In an individual's examination, intersubject variation is irrelevant, while position, time and leg 
effects become more important.

The inherent design of Experiment A was such that any effects solely attributable to differences between positions could not be completely separated from other possible differences between the groups of subjects allocated to the three positions. Nevertheless, since the allocation of subjects to the three groups, and hence positions, was made randomly, any differences between positions are likely to present genuine differences attributable to this factor. In Experiment B, when each of the young adults was investigated in all three positions, it was then possible to evaluate the effect of position, independent of all other factors. It can be seen from table 4 that position contributed very little to total variability in measurements from Experiment B, while in Experiment A position accounted for between $4.2 \%$ and $16 \%$ of the total variability according to the measurement being considered. The results from these experiments show that when subjects are studed in the laboratory in all three positions, position of itself does not have an important influence on the measurements. However, under hospital conditions in which it may be possible to study the patient in only one position (cf Experiment A), there may be some small effect of position on the result. To exemplify just how small this effect is, consider the following: the mean difference in relaxation index between positions 1 and 2 was 0.04 (table 5), whereas the mean values (from table 2 ) were of the order 1.5; thus the difference $(0.04)$ is small in proportion to actual measurements (range 1.3 to 1.7); therefore, in practical terms the position of the subject becomes relatively unimportant. In fig 3 the scatter of the results in the sitting position is greater than that obtained in the other positions. This agrees with the personal experience of the authors, as subjects, that it is more difficult to relax and allow the leg to swing freely in the sitting position. Again from personal experience the most comfortable position in which to take the test is the semi-supine, which also promises to be the best position in which to test patients.

The remaining factors assessed in the analysis of variance were leg and time effects. Reference to table 4 shows that neither contributed markedly to the total variability occurring in the data for any of the four measurements made. Further, their effects (table 5) on the various measures were either insignificant or so small as to be, practically, insignificant.

In conclusion, analysis of variance has shown that differences between individual subjects account for a major part of the total variabilities seen in all measurements taken. Other factors such as position, leg and time contribute far less effect to total variation. Though some of these effects can be shown to provide statistically significant differences they can, when considering an individual's investigation, to all practical purposes be ignored. In other words the pendulum test and measurements associated with it would seem to offer a relatively simple and quantitative test for clinical use. ${ }^{8}$

We thank all our subjects for their cooperation in this investigation, and Dr B Andrews and his colleagues at the Department of Bioengineering, University of Strathclyde, Glasgow, for generously making available their software package. Both Dr Andrews and ourselves (GCL/NJP) are willing to discuss our current software packages with anyone interested.

This work was in part financially supported by Norwich Eaton. We thank Mr J Winslade of Norwich Eaton for his continuing interest in our research.

\section{References}

1 Landau WM. Spasticity: What is it? What is it not? In: Feldman RG, Young RR, Koella WP, eds. Spasticity: Disordered Motor Control. Ciba Geigy International Symposium. Chicago: London: Year Book Medical Publishers 1981:17-24.

2 Webster DD. The dynamic quantitation of spasticity with automated integrals of passive motion resistance. Clin Pharmacol Therap 1964;5/6 part 2:900-8.

3 Duggan TC, McLellan DL. Measurement of muscle tone: a method suitable for clinical use. Electroencephalogr Clin Neurophysiol 1973;35:654-8.

4 Wartenberg R. Pendulousness of the legs as a diagnostic test. Neurology 1951;1:18-24.

5 Bajd T, Vodovnik L. Pendulum testing of spasticity. $J$ Biomed Eng 1984;6:9-16.

6 Mulvey N, Quinn J, Andrews BJ, Bajd T. A microcomputer based instrument for pendulum testing of spasticity. Dem: 19. In: Jordan MM, Perkins WJ, eds. Computer-aided Biomedical Imaging and Graphics Physiological Measurement and Control. London: The Biological Engineering Society 1984.

7 Lawson D, Leslie GC, Part NJ. An assessment of the use of the Wartenberg pendulum test in an elderly population. J Physiology (Lond) 1986;373:80P.

8 Brown RA, Lawson DA, Leslie GC, et al. Does the Wartenberg pendulum test differentiate quantitatively between spasticity and rigidity? A study in elderly stroke and Parkinsonian patients. J Neurol Neurosurg Psychiatry 1988;51:1178-86.

9 Nie NH, Hull CH, Jenkins JG, Steinbrenner K, Bent DH. SPSS Statistical Package for the Social Sciences. London: New York: McGraw Hill, 1975.

10 Bowman B, Bajd T. Influence of electrical stimulation on skeletal muscle spasticity. In: Popovic D, ed. Proceedings of the Seventh International Symposium on External Control of Human Extremities. Belgrade: Yugoslav Committee for Electronics and Automation, 1981:567-76.

11 Lakie M, Walsh EG, Wright GW. Passive wrist movements-a large thixotropic effect. J Physiol (Lond) 1980;300:36P. 